\title{
An Expert System to build Cognitive Model of an IT Student using Artificial Neural Networks for Predicting Placements during Campus Recruitments
}

\author{
Hameeda Khatoon ${ }^{1}$, V. Chandra Prakash ${ }_{2}$, JKR Sastry ${ }^{3}$, B. Tirapathi Reddy ${ }^{4}$ \\ ${ }^{1}$ Koneru Lakshmaiah Education Foundation, Vaddeswaram, AP, India, hameeda8715@ gmail.com \\ ${ }^{2}$ Koneru Lakshmaiah Education Foundation, Vaddeswaram, AP, India, vchandrap@kluniversity.in, \\ ${ }^{3}$ KoneruLakshmaiah Education Foundation, Vaddeswaram, AP, India, drsastry@kluniversity.in, \\ ${ }^{4}$ KoneruLakshmaiahEducation Foundation, Vaddeswaram, AP, India, tirapathireddyb@ kluniversity.in
}

\begin{abstract}
Careers that suits students' needs to be predicted and the students counselled to opt for those suitable careers. An under-graduate student of IT studies has to choose many courses to complete his/her under-graduate program. But, there arevery few courses among them that influence the probability of getting placement during campus drives. Career prediction system needs to consider different aspects related to cognition of the student. An expert system is required for prediction.
\end{abstract}

In this paper, considering the influencing courses an Expert System that uses cognitive metrics is proposed and presented to build a Cognitive Model of a student. The Expert system trains an artificial neural network using the cognitive model and predicts the probability of getting placements for a student in the Target Year.

Keywords: Expert System, Cognitive metrics, Artificial Neural Networks, predicting jobs, Student, Cognitive Model

\section{INTRODUCTION}

\subsection{Expert System}

An Expert System (ES) is a program that simulates human expert behaviour. ES provides expeditious expert advice and is one of the important research domains in AI. ES utilizes the knowledge stored in a knowledge base to deal with the problems that generally need human expertise for problem solving. The ES proposed in this paper considers the historical data of academic performance and placement results of all the students' of previous three years' w.r.t the target year and trains an Artificial Neural Network (ANN). Subsequently the trained ANN predicts the probability of getting placement for a student of the target year.

\subsection{Cognitive Model}

There are many definitions for the word "cognitive model". A cognitive model is an approximation to human/animal cognitive processes for the purpose of comprehension. The Cognitive Model is the computational depiction of the human reasoning process or behaviour. The cognitive model represents the psychological factors viz. logical thinking ability, communication ability in different languages, intelligence, problem solving ability, memory power, patience and perseverance, learning ability, etc. It also represents the knowledge levels in different domains or courses or hands-on skills.

\subsection{Cognitive Metric}

A metric is the standard of measurement. It is a measure of perceptible evaluation for comparing and tracking the conduct of a performance. The metric used in this paper evaluates the academic performance of a student with respect to a psychological factor(s). A cognitive metric quantitatively estimates a psychological factor of the cognitive model of a student.

\subsection{Artificial Neural Network}

An ANN is a computational model based on the configuration and role of biological neural networks in the brain. ANN are designed to replicate or simulate the way the human brain interprets and processes the information. An ANN is composed of artificial neurons called units, organized in a sequence of layers viz. the input layer, the hidden layer(s), and the output layer. The first layer is the input layer that receives the data that the network wants to process or gain the information about. The hidden layer is the second layer in the ANN and is present between the input and the output layer and is invisible to the outside systems. There may be one or more hidden layers. The output layer is mainly responsible for generating the output results. An 
Hameeda Khatoon et al., International Journal of Emerging Trends in Engineering Research, 8(3), March 2020, 838- 846

ANN is popular for classification and prediction problems in machine learning.

\subsection{Prediction of Job}

Every student aims to secure a job after his/her graduation. Thus, campus placement plays a crucial role for the final year students of any university or college. Generally, a human expert viz. counsellors or placement trainers predict the opportunities of a student for getting a job. A human expert predicts the chances of a student getting a job through experience or expertise but there is no scientific basis for such type of prediction. To err is human i.e., there may be some error in human prediction. It is better to develop an expert system that can predict the probability of getting placement for a student by considering the inputs viz. academic performance results of placements and exhibiting human-like reasoning by using statistical techniques, cognitive models, machine learning techniques, etc. ANN's are very popular for prediction.

\subsection{Problem Definition}

To develop an ES that extracts the knowledge from the historical data of academic performance and campus placement results of students of an institution and build a cognitive model of an IT student. The ES trains an ANN with those models, so that the ANN can predict the probabilities of getting a placement for outgoing IT students of the current year.

\section{RELATED WORK}

\subsection{Expert System}

Balasubramanyam, S. et al.[1] developed a rule based expert system which suggests a suitable branch based on the interest of students. Gupta, et al. [2] developed an expert system that evaluates the performance of students' using the machine learning techniques. Drigas, et al. [3] developed an expert System that suggests the suitable job(s) for an unemployed person. Walek et al. [4] developed a web based expert system which selects the suitable applicant for a given job.El Haji et al. [5] developed a multi-expert system to predict the performance of students in the introductory course of computer science. Khanna, Satvika, Akhil Kaushik, and Manoj Barnela [6] developed an expert system which is useful in various domains of the education field viz. educational planning, decision-making ability, and tutor training. V. Chandra Prakash et al. [7] developed an expert system to predict a suitable career of a student by assessing the memory power. V. Chandra Prakash et al. [8] developed an expert system that predicts the suitable job for a student based on the performance of the student in various games viz. Tic-Tac-Toe, 8-puzzle, Sudoku, Sokoban etc. V. Chandra Prakash et al. [9] developed an expert system for career prediction of a student based on the performance of the student in the N-Coin puzzle.

\subsection{Cognitive Metric}

De Alwis et al. [10] proposed a cognitive metric to quantitatively measure "Programming Task Difficulty". Shovon et al. [11] proposed a cognitive metric which is useful for diagnosing the cognitive impairment of a patient.

\subsection{Cognitive Model}

Lent et al .[12] presented two studies in which the social cognitive model for self- management of career is applied to career analysis and the decision making aspect of college students. Chandra Prakash V et al. [13] developed an Expert System that assesses the psychological factors of an IT student viz. speed of problem solving, the learning ability, and patience etc. using an 8-puzzle game and builds a cognitive model of a student. The expert system uses that cognitive model and predicts the suitable jobs in the Software industry for the student. Chandra Prakash V et al. [14] developed an Expert system that builds the cognitive model of an IT student using crypt-arithmetic game. Chandra Prakash V et al. [15] analysed how far the Sokoban game is useful for building a cognitive model to predict the career of the students. Chandra Prakash V et al. [16] investigated the applicability of the Sudoku game to assess the student career. J. Sasi Bhanu et al. [17] designed and developed a cognitive model for career guidance of students' by playing the TicTac-Toe game. Nani Sri Handayani et al. [18] designed and developed a cognitive model for Collaborative Writing online. Pascal Boyer and Michael Bang Petersen [19] designed and developed a cognitive model for folk-economic trust.

\subsection{Artificial Neural Network (ANN)}

Tao Yong-hong [20] predicted the quality of college employment using Back-Propagation Neural Network. A Santoro et al. [21] developed a simple module of the neural network for relative reasoning. Liang, Ming, and Xiaolin $\mathrm{Hu}$ [22] explain about the recognition of the objects by recurrent neural networks. Ahmed Sulaiman, M.Alharbi and Elisede Doncker [23] performed the twitter emotional analysis using the deep neural network. M Bisquert et al. [24] predicted the danger of forest fire in Galicia by applying the neural networks and the logistic regression to MODIS data.

\subsection{Job Prediction}

Nedhal A. Al-Saiyd et al. [25] proposed a system for predicting the suitable IT job for a student based on the skills, experience and knowledge of a graduate student using Artificial Neural Networks (ANN). SudheepElayidom et al. [26] proposed a framework using data mining techniques to predict the chances of student's placement. PratiyushGuleria, Manu Sood [27] predicted the placement results of the 
students using Bayesian classification. Kasem Seng and Akram M. Zeki [28] developed a CGEM system to provide job opportunities for students. Tripti Mishra et al. [29] predicted the student's employability using the data mining techniques. T. Jeevalatha et al. [30] performed detailed analysis of undergraduate students on placement selection by using algorithms of Decision Tree. NeelamNaik et al. [31] predicted the final result of the students along with the placement of the students with the help of classification algorithms. Savita Bakare et al. [32] applied Fuzzy logic and K Nearest Neighbor on the students' database to predict the campus placement. S Revathy et al. [33] stated an approach to placement opportunities for a specific company employing data mining techniques. N Puri et al. [34] applied ID3 algorithm for prediction of student's campus placements Kalbande et al. [35]

\section{ANALYSIS AND DESIGN OF EXPERT SYSTEM}

The goal of the research in this paper is to predict the probability of getting placement for an IT student.

\subsection{Cognitive Metrics and Cognitive Model}

The authors have proposed two hypotheses in this paper. The first hypothesis is that the probability of getting placement for a student in campus drives is proportional to the Cumulative Grade Point Average (CGPA) of the student given by the University. The CGPA is a floating point number $0<=C G P A<=10$. The authors have proposed a cognitive metric termed as M_UCGPA (Metric for University Cumulative Grade Point Average). The variable M_UCGPA has twenty one discrete values viz. 0.0, 0.5, $1.0, . ., .6 .5,7,7.5,8,8.5,9,9.5,10$ (each represents a class). The M_UCGPA is computed by rounding UCGPA (University Cumulative Grade point Average) to the nearest discrete value. The authors have proposed the second hypothesis which is as follows.

Earlier, some of the authors of this paper have published a few research papers [7][8][9][13][14][15][16][35] [36] [37] [38] [39][40] [41] on how to build a cognitive model of a student in different ways and how to assess career of a student based on those cognitive models. In continuation of this research work, the authors proposed a new way of building a cognitive model of a student which can be subsequently used for assessing the probability of getting placement for a student. The authors have consulted IT professionals, placement experts, the senior faculty members, counsellors\& students and came up with the hypothesis that the probability of getting placement for a student depends on two psychological factors of the student viz. the Communication ability in English and Logical thinking ability of a student. The authors proposed a cognitive metric termed as MCE to measure the communication ability in English of the student by considering the marks of the student in the subjects
Communication and English. The authors proposed a cognitive metric termed as MLT to measure logical thinking ability of a student by considering the marks of $\mathrm{C}$ programming, Object Oriented Programming $(\mathrm{C}++$ or Java or Python) and Data Structures. These two cognitive metrics are combined forming a single cognitive metric termed as MCELT. The variable MCELT has twenty one discrete values viz. $0.0,0.5,1.0,, . . ., 6.5,7,7.5,8,8.5,9,9.5,10$ (each represents a class). The cognitive model is designed to assess the psychological factors of the student namely logical thinking ability, Communication ability. Table 1 is an example the cognitive model of a student.

Table 1: An example of Cognitive Model of a Student

\begin{tabular}{|c|l|c|}
\hline S. No. & Psychological Factor & $\begin{array}{l}\text { Score } \\
\text { (Max 10) }\end{array}$ \\
\hline 1 & Communication ability in English & 8 \\
\hline 2 & Logical Thinking ability & 9 \\
\hline
\end{tabular}

\subsection{Dataset}

The dataset-2016 consists of marks of all subjects, and placement results (of thirty important companies) of 2016 outgoing IT students collected from different primary sources. Similar data is present in dataset-2017, dataset-2018 anddataset-2019. The dataset-2016, dataset-2017 and dataset2018 are combined into a dataset termed as dataset16_17_18.

\subsection{Predicting Probability}

All the records of students of the dataset-16_17_18 are classified into different classes using the cognitive metric MCELT\{Metric for Communication in English and Logical thinking Ability\}. Generally, the probability for getting placement is computed as $n / d$ where the numerator, $n$, represents the number of students who got selected in campus placements and the denominator, $\mathrm{d}$, is the number of students who appeared for placements. The statistical probability, $\mathrm{p}$, ranges between $0<=\mathrm{p}<=1$. During the training phase the ANN is trained with the input asclass number and their corresponding probabilities. The accuracy of the ANN for training is $99 \%$. During the testing phase the inputs given to the trained ANN is class number and ANN predicts the probability of student getting placement for that class. The classes which comprisea very few number of students should not be considered for predicting the probabilities statistically. 


\subsection{Program architecture design}

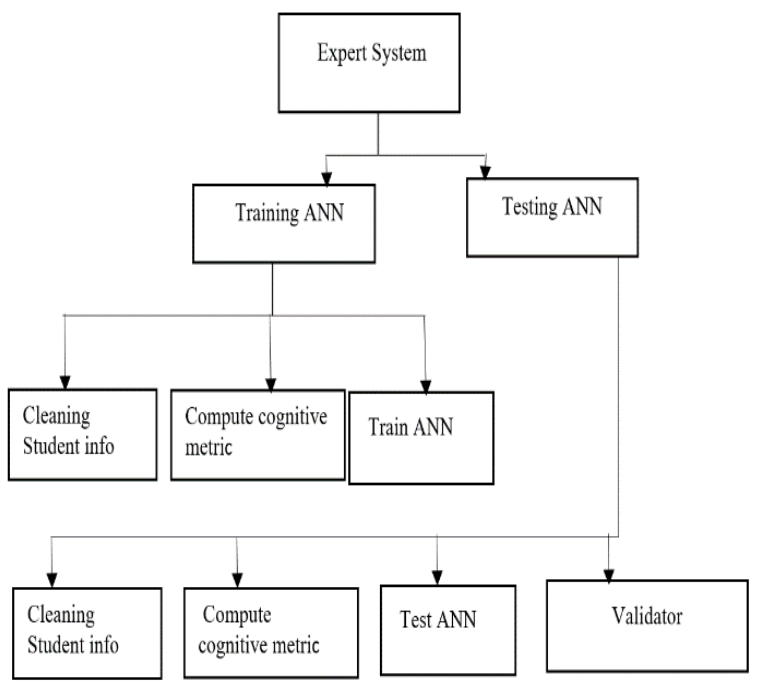

Figure 1: Program Architecture Design of ES

Figure 1 describes the program architecture design of the proposed ES. TheEShas two modules; one is training ANN and the second is testing ANN. In the first module, thedataset_16_17_18 is cleaned, the cognitive metric, MCELT, is computedfor every student. All student records in the dataset are classified into different classesusing MCELT and probability of getting placementfor each class is calculated. The ANN is trained with class number as input and the probability of getting placement as output. In the second module,the dataset-2019 is cleaned and classified using MCELTand given as input to the trained ANN.The trained ANN predicts the probability of getting placement. Finally, the Validator computes the standard deviation of the predicted result from the actual result.

\subsection{Architecture of ANN}

The Architecture of ANN consists of one input layer in which one unit is present, two hidden layers with seventy units in each hidden layer and one output layer with six units in the layer. Figure 2 describes the Architecture of ANN. The ANN is fully trained with the dataset-16_17_18. It can preict the probabilities of getting placement for the classes in the dataset-19.

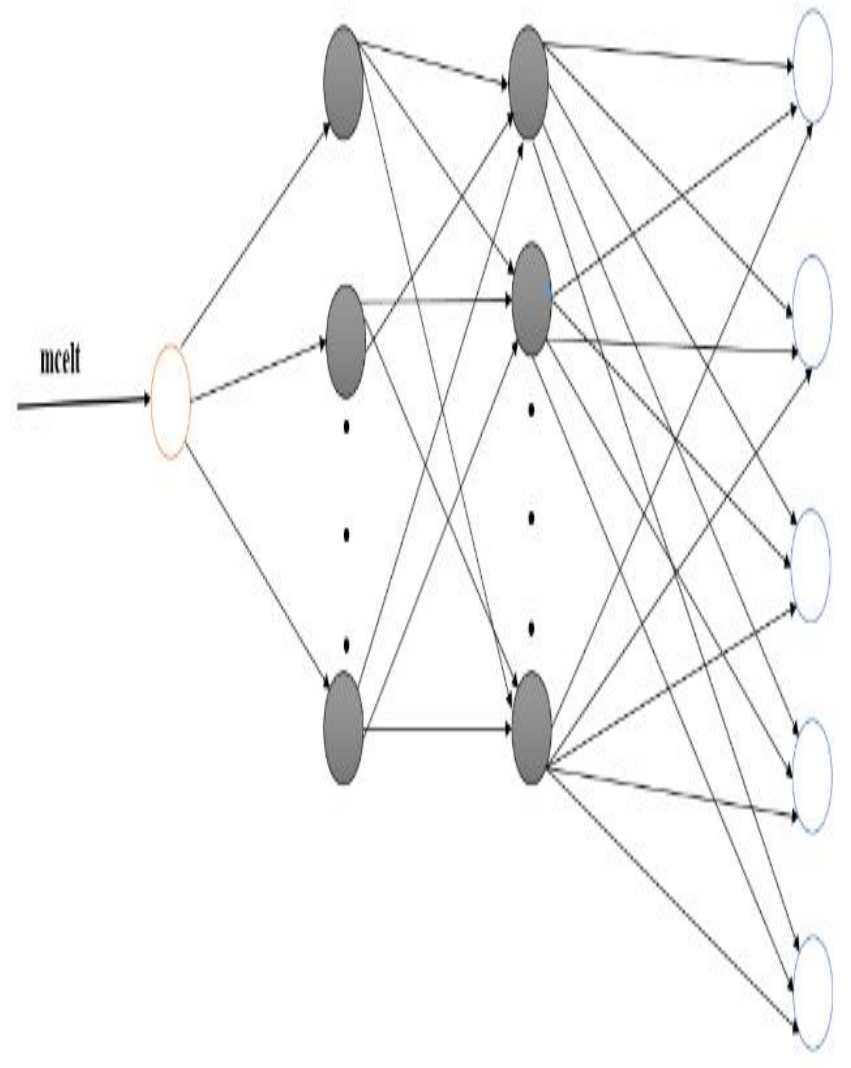

Figure 2: Architecture of ANN

\subsection{Design of Pre-processor}

The pre-processor cleans the dataset- 2016, dataset-2017 and dataset-2018 i.e. it retains the data of students' who have registered for Campus Recruitment training (CRT) and removes the unwanted data.

\subsection{Design of Postprocessor}

The post processor is used in the testing phase of ANN (Artificial Nueral Network. After the ANN predicts the probabilities, the post processor extracts those results (predictions) from the neural network. It normalizes the predictions (referred as predicted results PR) and posts the predictions into an excel file.The procedure for normalization is as follows:

\section{The Selection percentage $(\mathrm{SP})=(\mathbf{n} / \mathbf{d}) * 100(1)$}

where $\mathrm{n}=$ number of students selected

$\mathrm{d}=$ number of students appeared for placement

For example,

$$
\operatorname{SP}(2019)=(456 / 644) * 100=71 \%
$$

SP (for the previousyears 2016,2017and2018)

$=(621 / 1120) * 100=55 \%$ 
Hameeda Khatoon et al., International Journal of Emerging Trends in Engineering Research, 8(3), March 2020, 838- 846

Normalization factor(NF)=SP (2019) / SP (previous years)

(2)

For example, NF (2019) = SP(2019)/ SP(previous years $)=71 / 55=1.2$

Predicted Results (PR),after Normalization is given below

$\operatorname{PR}(2019)=\operatorname{PRANN}(2019) * N F(2019)(3)$

Where PRANN (2019) is the predicted result by the ANN

\section{RESULT ANALYSIS}

Generally, everyone believes that the probability of campus placement is proportional to the university CGPA of a student. In order to prove or disprove this hypothesis the probabilities of getting placement are computed for all students using M_UCGPA metric as shown in Table 2.

Table 2: M_UCGPA vs Probability for Campus Placement

\begin{tabular}{|c|c|c|c|c|}
\hline S. No. & $\begin{array}{c}\text { Clas } \\
\mathbf{\text { Num }} \\
\text { ber } \\
\mathbf{X}- \\
\text { axis) }\end{array}$ & $\begin{array}{c}\text { No. of } \\
\text { students } \\
\text { appeared } \\
\text { for } \\
\text { placements } \\
(\mathbf{d})\end{array}$ & $\begin{array}{c}\text { No. of } \\
\text { students } \\
\text { Elected } \\
(\mathbf{n})\end{array}$ & $\begin{array}{c}\text { Probability } \\
(\mathbf{n} / \mathbf{d}) \\
(\mathbf{Y} \text {-axis) }\end{array}$ \\
\hline 1. & 6.50 & 35 & 17 & $49 \%$ \\
\hline 2. & 7.00 & 167 & 63 & $38 \%$ \\
\hline 3. & 7.50 & 280 & 133 & $48 \%$ \\
\hline 4. & 8.00 & 307 & 178 & $58 \%$ \\
\hline 5. & 8.50 & 212 & 125 & $59 \%$ \\
\hline 6. & 9.00 & 119 & 76 & $64 \%$ \\
\hline 7. & 9.50 & 35 & 24 & $69 \%$ \\
\hline 8. & 10.0 & 3 & 2 & $67 \%$ \\
\hline
\end{tabular}

A bar chart is drawn (refer Figure 3) in which the class numbers (values of M_UCGPA) are taken on $\mathrm{x}$-axis and the corresponding probabilities are taken on y-axis. As discussed in section 3.3 of this paper, the class 10 of the M_UCGPA is not considered as it consists of very less number of students and the modified bar chart is drawn in Figure. 4. From Figure 4, it is observed that the class 6.5 of M_UCGPA metric has higher probability than class 7 which is an anomaly and we can't predict the results with this anomaly, the authors tried to train a neural network but the accuracy is very low.
Table 3 : MCELT vs Probability for Campus Placement

\begin{tabular}{|r|c|r|r|c|}
\hline $\begin{array}{c}\text { S. } \\
\text { N } \\
\text { o. }\end{array}$ & $\begin{array}{c}\text { Class } \\
\text { Number } \\
\text { (X-axis) }\end{array}$ & $\begin{array}{c}\text { No. of } \\
\text { students } \\
\text { appeared } \\
\text { for } \\
\text { placements } \\
\text { (d) }\end{array}$ & $\begin{array}{c}\text { No. of } \\
\text { student } \\
\text { s } \\
\text { selecte } \\
\text { d } \\
\text { (n) }\end{array}$ & $\begin{array}{c}\text { Probability } \\
\text { (n/d) } \\
\text { Predicted } \\
\text { Result(PR) }\end{array}$ \\
\hline 1. & 6.50 & 16 & 8 & $65 \%$ \\
\hline 2. & 7.00 & 175 & 62 & $45 \%$ \\
\hline 3. & 7.50 & 206 & 94 & $59 \%$ \\
\hline 4. & 8,00 & 370 & 200 & $70 \%$ \\
\hline 5. & 8.50 & 175 & 104 & $76 \%$ \\
\hline 6. & 9.00 & 173 & 120 & $89 \%$ \\
\hline 7. & 9.50 & 36 & 26 & $93 \%$ \\
\hline 8. & 10.00 & 4 & 3 & $96 \%$ \\
\hline
\end{tabular}

Hence, the new cognitive metric MCELT is used to classify the students into different classes and the probabilities of getting placement for each class are computed (as shown in table 3). A bar chart is drawn (refer Figure 5) in which the class numbers (values of M_UCGPA) are taken on $\mathrm{x}$-axis and the corresponding probabilities of getting placement are taken on y-axis. The classes 6.5 and 10 cannot be considered as illustrated in Section 3.3. So, a modified bar chart is redrawn (shown in fig. 6). It is observed that the classes and their probabilities of getting placement are proportional. The predicted probabilities of getting placement for the 2019 outgoing IT students and the actual probabilities of getting placement are given in Table 4 and shown in Figure. 7. The standard deviation is found out to be 5.1. Hence, the proposed metric MCELT can be used to predict the

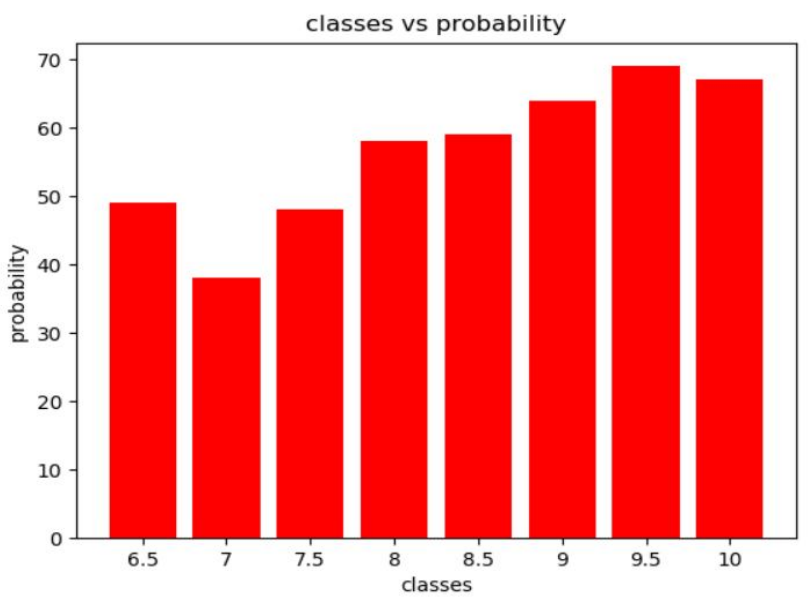

Figure 3: M_UCGPA metric vs probability 


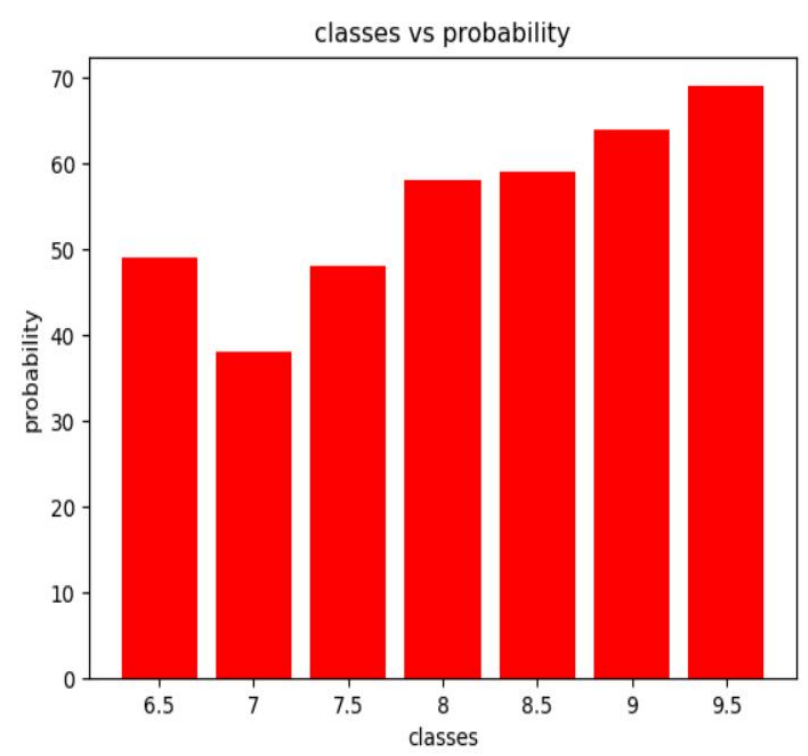

Figure 4: modified m_ucga vs probability

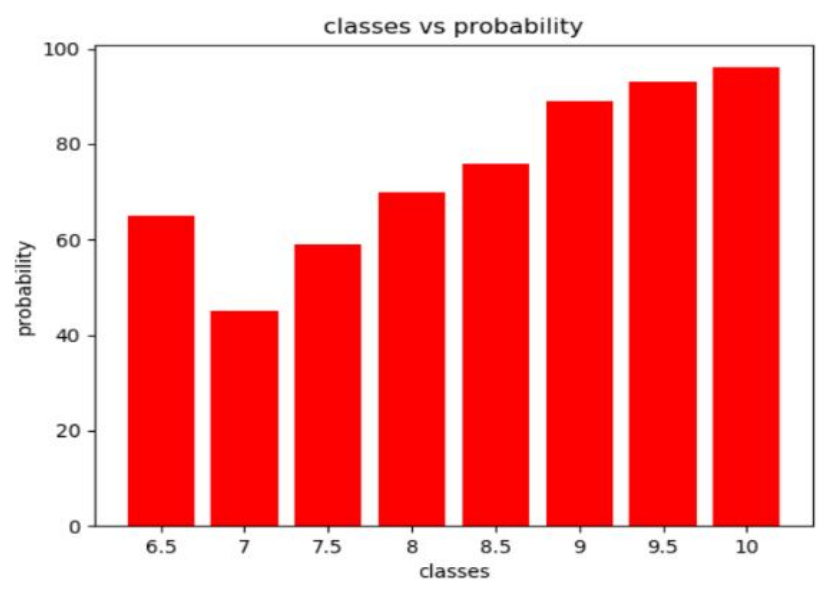

Figure 5: MCELT metric vs probability

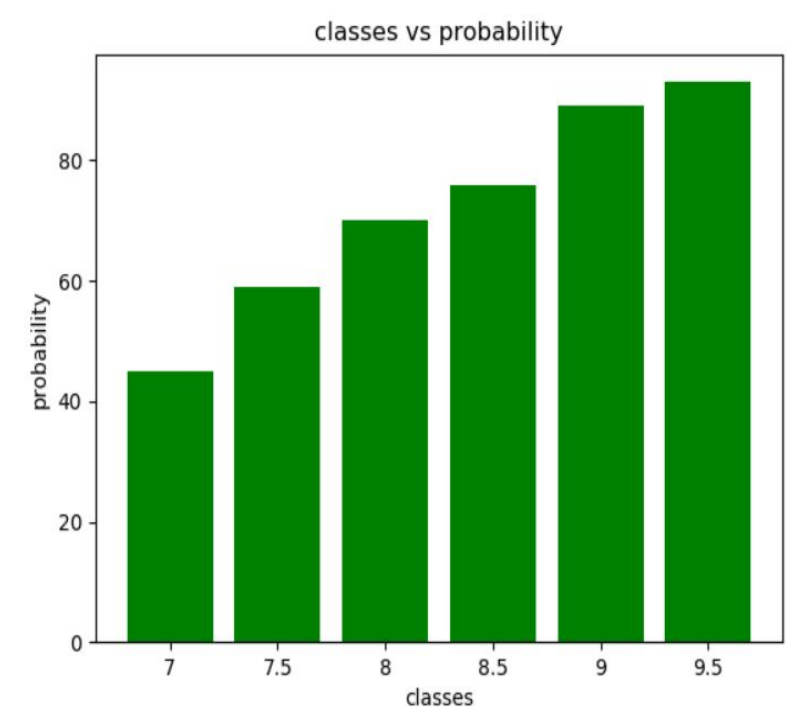

Figure 6: MCELT modified vs probability
Table 4: Predicted Result vs Actual Result

\begin{tabular}{|c|c|c|c|}
\hline S. No. & $\begin{array}{c}\text { Class } \\
\text { Number }\end{array}$ & $\begin{array}{c}\text { Predicted } \\
\text { Result } \\
\text { (PR) }\end{array}$ & $\begin{array}{c}\text { Actual Result } \\
\text { (AR) }\end{array}$ \\
\hline 1. & 7.00 & $45 \%$ & $41 \%$ \\
\hline 2. & 7.50 & $59 \%$ & $65 \%$ \\
\hline 3. & 8.00 & $70 \%$ & $84 \%$ \\
\hline 4. & 8.50 & $76 \%$ & $94 \%$ \\
\hline 5. & 9.00 & $89 \%$ & $94 \%$ \\
\hline 6. & 9.50 & $93 \%$ & $100 \%$ \\
\hline
\end{tabular}

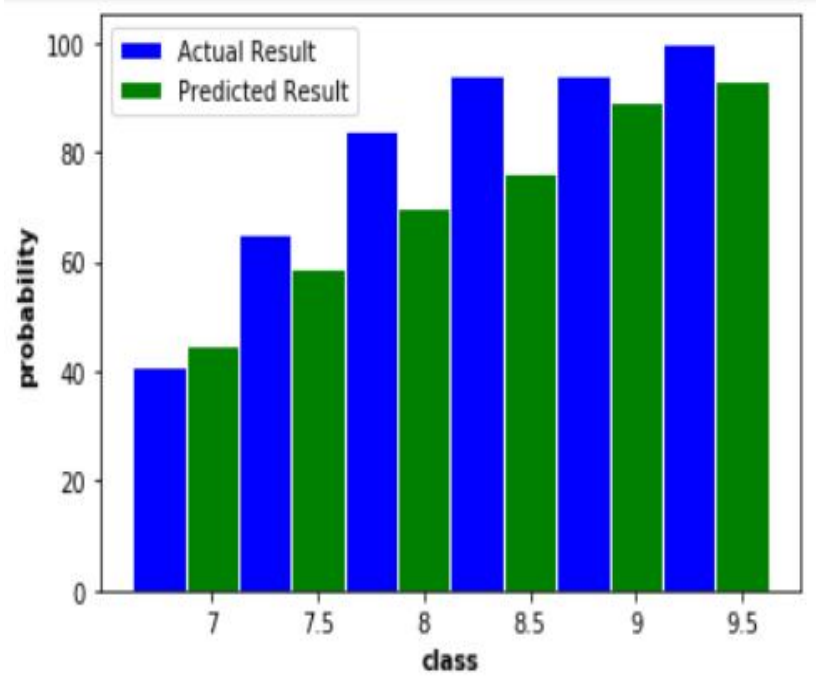

Figure 7 : Actual result versus predicted result

\section{CONCLUSION}

\subsection{Conclusion}

There is a need for a model for predicting suitable carers to the IT students so that the students can be prepared such that they get place as per their suitability

The Expert System that considers the academic performance of a student is required to predict his/her chances of being placed.

Different kinds of cognitive metrics required which can be used for measuring cognitive level of the students

ANN is one of the excellent techniques that can be used for prediction through the process of classification. The ANN model can be effectively used for predicting the placement probability of an IT student. 
The Model has been experimented across several datasets and the predicted results are very close to the actual placement results.

\subsection{Future Scope}

The present research is focused on predicting the probability of getting placements for Students of Computer Science and Engineering discipline. The design can be extended to students of other disciplines viz. Electronics and Communication Engineering, Mechanical Engineering, MBA, etc.

\section{ACKNOWLEDGEMENT}

This research work is part of the research project titled "Development of an expert system for student career assessment based on cognitive models" funded by Department of Science and Technology - Cognitive Science Research Initiative scheme(CSRI) (Sanc- tion order No SR/CSRI/129/2014(G)) of Government of India. The PI of the project is Dr. V. Chandra Prakash. The CO-PI of the project is Dr. J.K.R. Sastry. K L University provides the infra-structure for the project.

\section{REFERENCES}

1. Balasubramanyam, S., D. PadmajaUsharani, A. Harsha Vardhan Reddy, DanthalaSwetha, Gurram Narendra Santosh Kumar, K. Anusha, and SkHasane Ahammad. "Selecting a College Academic Branch-a Design Decision Taking System for Student Career Selection." International Journal of Engineering \& Technology 7 , no. 4.19 (2018): pp 323-328.

2. Gupta, Yogesh, and Ghanshyam Raghuwanshi. "Student Performance Evaluation Expert System Using Machine Learning to Make Cognitive Decisions." International Conference on Sustainable Computing in Science, Technology \& Management (2019). https://doi.org/10.2139/ssrn.3356244

3. Drigas, Athanasios, Stelios Kouremenos, Spyros Vrettos, John Vrettaros, and Dimitris Kouremenos. "An expert system for job matching of the unemployed." Expert Systems with Applications (Elsevier) 26, no. 2 (2004): pp 217-224.

4. Walek, Bogdan, OndrejPektor, and Radim Farana. "Proposal of the web application for selection of suitable job applicants using expert system." In Computer Science On-line Conference (Springer), pp. 363-373. Cham, 2016. https://doi.org/10.1007/978-3-319-33622-0_33

5. El Haji, Essaid, AbdellahAzmani, and Mohamed El Harzli. "Multi-expert system design for educational and career guidance: an approach based on a multi-agent system and ontology." International Journal of Computer Science Issues (IJCSI) 11, no. 5 (2014): 46.

6. Khanna, Satvika, Akhil Kaushik, and Manoj Barnela. "Expert systems advances in education." In Proceedings of the National Conference on Computational Instrumentation NCCI-2010. CSIO, pp. 109-112. 2010.

7. V. Chandra Prakash, J. K. R. Sastry, V. Kantharao, V. Sri-harshini, G. Sriram, and C. H. V. S. Ganesh. "An Expert System to assess Memory Power of a Student for Selection of a Suitable Career." Journal of Advanced Research in Dynamical and Control Systems, ISSN (1943).

8. V. Chandra Prakash, J.K.RSastry, G.Reeshmika, M.Pavani, P.ChikithaSree, J.S Ravi Teja. "Development of a Comprehensive and Integrated Expert System for Career Assessment based on Cognitive models." International Journal of Emerging Trends in Engineering Research 7, no.11 (2019): pp 617-627 https://doi.org/10.30534/ijeter/2019/347112019

9. V. Chandra Prakash, J.K.R. Sastry, B. Tirapathi Reddy, J. S. Ravi Teja, A. BalaVenkatesh, M. S. K. Vamsi Varma. "An Expert System for building a Cognitive and Career Prediction model based on N-Coin Puzzle Game." International Journal of Emerging Trends in Engineering Research 7, no.11 (2019): pp 410-416 https://doi.org/10.30534/ijeter/2019/037112019

10. De Alwis, Brian, Gail C. Murphy, and Shawn Minto. "Creating a cognitive metric of programming task difficulty." In Proceedings of the 2008 international workshop on Cooperative and human aspects of software engineering, pp. 29-32. 2008.

11. Shovon, MdHedayetul Islam, D. Nanda Nandagopal, RamasamyVijayalakshmi, Jia Tina Du, and Bernadine Cocks. "Towards a cognitive metric using normalized transfer entropy." BioMedCom 2014 Conference, Harvard University.

12. Lent, Robert W., IjeomaEzeofor, M. Ashley Morrison, Lee T. Penn, and Glenn W. Ireland. "Applying the social cognitive model of career self -management to career exploration and decision making." Journal of Vocational Behavior, pp 47-57. https://doi.org/10.1016/j.jvb.2015.12.007, 2016.

13. V. Chandra Prakash, J. K. R. Sastry, K. Anusha, P. Ashok Kumar, N. Venkatesh, and G. Ravi Teja. "Expert system for building cognitive model of a student using 8-puzzle game and for career assessment." International Journal of Engineering \& Technology 7, no. 2.27 (2018): 113-117.

14. V. Chandra Prakash, V. Kantharao, J. K. R. Sastry, and V. Bala Chandrika. "Expert system for building Cognitive model of a student using Crypt Arithmetic game and for Career Assessment." International Journal of Recent Technology and Engineering ISSN: 2277-3878, Volume-7, Issue-6S4, 2019

15. V. Chandra Prakash, and J. K. R. Sastry. "A critical study on applicability of sokoban game for building the cognitive model of a student for career assessment." International Journal of Engineering \& Technology 7 , no. 1.1 (2018): 260-264. 
Hameeda Khatoon et al., International Journal of Emerging Trends in Engineering Research, 8(3), March 2020, 838- 846

16. V. Chandra Prakash, J. K. R. Sastry, K. B. Anusha, A. B. Spandana, N. Dhatrija, and V. Nikhil. "Applicability of Sudoku game for building the cognitive model of a student for career assessment-an analytical study." International Journal of Engineering \& Technology 7 , no. 1.1 (2018): 246-251. https://doi.org/10.14419/ijet.v7i1.1.9479

17. Bhanu, J. Sasi, J. K. R. Sastry, and V. Chandra Prakash. "Assessing the intelligence of a student through tic-tactoe game for career guidance." International Journal of Electrical and Computer Engineering (IJECE) 9, no. 6 (2019): 5545-5551.

18. Handayani, Nani Sri, and JIIrSutami. "A Cognitive Model of Online Collaborative Writing." International Journal of Education and Research Vol. 4 No. 102016.

19. Boyer, Pascal, and Michael Bang Petersen. "Folkeconomic beliefs: An evolutionary cognitive model." Behavioral and Brain Sciences 41 (2018).

20. Yong-Hong, Tao. "College employment quality prediction method based on BP neural network." In 2014 7th IEEE International Conference on Intelligent Computation Technology and Automation, pp. 129-132. 2014

21. Santoro, Adam, David Raposo, David G. Barrett, Mateusz Malinowski, RazvanPascanu, Peter Battaglia, and Timothy Lillicrap. "A simple neural network module for relational reasoning." In Advances in neural information processing systems, pp. 4967-4976. 2017.

22. Liang, Ming, and Xiaolin Hu. "Recurrent convolutional neural network for object recognition." In Proceedings of the IEEE conference on computer vision and pattern recognition, pp. 3367-3375. 2015.

23. Alharbi, Ahmed Sulaiman M., and Elise de Doncker. "Twitter sentiment analysis with a deep neural network: An enhanced approach using user behavioral information." Cognitive Systems Research 54 (2019): 50-61.

24. Bisquert, Mar, Eduardo Caselles, Juan Manuel Sánchez, and Vicente Caselles. "Application of artificial neural networks and logistic regression to the prediction of forest fire danger in Galicia using MODIS data." International Journal of Wildland Fire 21, no. 8 (2012): 1025-1029.

https://doi.org/10.1071/WF11105

25. Al-Saiyd, Nedhal A., and Amjad S. Al-Takrouri. "Prediction of it jobs using neural network technique." Ubiquitous Computing and Communication Journal (2014) (ISSN 1992-8424)

26. Elayidom, Sudheep, Sumam Mary Idikkula, and Joseph Alexander. "A generalized data mining framework for placement chance prediction problems." International Journal of Computer Applications 31, no. 3 (2011): 0975-8887.

27. Guleria, Pratiyush, and Manu Sood. "Predicting student placements using Bayesian classification." In 2015
Third IEEE International Conference on Image Information Processing (ICIIP), pp. 109-112, 2015.

28. Seng, Kasem, and Akram M. Zeki. "Career Guidance and Employment Management System." In 2014 3rd IEEE International Conference on Advanced Computer Science Applications and Technologies, pp. 73-78. 2014.

29. Mishra, Tripti, Dharminder Kumar, and Sangeeta Gupta. "Students' Employability Prediction Model through Data Mining." International Journal of Applied Engineering Research 11, no. 4 (2016): 2275-2282.

30. Jeevalatha, T., N. Ananthi, and D. Saravana Kumar. "Performance analysis of undergraduate students' placement selection using decision tree algorithms." International Journal of Computer Applications 108, no. 15 (2014). https://doi.org/10.5120/18988-0436

31. Naik, Neelam, and Seema Purohit. "Prediction of Final Result and Placement of Students using Classification Algorithm." International Journal of Computer Applications 56, no. 12 (2012).

32. Mangasuli, PS Bakare, "Prediction of Campus Placement Using Data Mining Algorithm-Fuzzy logic and $\mathrm{K}$ nearest neighbor," International Journal of Advanced

Research in Computer and Communication Engineering 5, no. 6 (2016): 309-312.

33. Revathy, S., G. Roopika, R. Rishitha, and P. Revathy. "An approach to suggest company specific placement opportunities using data mining techniques." International Journal of Computer Science and Mobile Computing (2320-088X) vol-6 (2017).

34. Puri, Namita, DeepaliKhot, and PratikshaShinde, KishoriBhoite, Prof.DeepaliMaste "Student Placement Prediction Using ID3 Algorithm." International Journal for Research in Applied Science \& Engineering Technology, Volume 3, Issue III (2015).

35. Dr. J. Sasi Bhanu, Dr. JKR Sastry, B. Sunitha Devi3, Dr. V Chandra Prakash, International Journal of Emerging Trends in Engineering Research, Volume 7, No.6 Pp. 25-31, 2019

36. Dr. Sasi Bhanu, J, Dr. Baswaraj D, Mrs. Sunitha Devi Bigul, Dr. JKR Sastry, Career Prediction through Cognitive Models using Sudoku Game - The Assessment of Applicability, International Journal of Emerging Trends in Engineering Research, Volume 7, Issue 11, Pp. 473-48, 2019 https://doi.org/10.30534/ijeter/2019/127112019

37. Dr. Sasi Bhanu1 J, Dr. Baswaraj D2, Sunitha Devi Bigul3, Dr. JKR Sastry, Generating Test cases for Testing Embedded Systems using Combinatorial Techniques and Neural Networks based Learning Model, International Journal of Emerging Trends in Engineering Research, Volume 7, No. 11 Pp. 417-429, 2019

https://doi.org/10.30534/ijeter/2019/047112019 
Hameeda Khatoon et al., International Journal of Emerging Trends in Engineering Research, 8(3), March 2020, 838- 846

38. Dr. J Sasi Bhanu, M. Lakshmi Prasad, Dr. J. K. R. Sastry, Combinatorial Neural Network Based a Testing of an Embedded System, Jour of Adv Research in Dynamical \& Control Systems, Vol. 10, 07-Special Issue, 2018

39. V, Chandra Prakash, M. R Narasinga Rao, M. R. Sindhu Saraswathi, N. Dorothy William. T. Lavanya Kumari, K Venkata Sujith, Finding the effectiveness of Prioritised Test Suite usingNeural Network, Indian Journal of Science and technology, Volume 9, Issue 44, PP. , 2016

40. Prakash, K.B. \&DoraiRangaswamy, M.A. 2016, "Content extraction studies using neural network and attribute generation", Indian Journal of Science and Technology, vol. 9, no. 22, pp. 1-10. https://doi.org/10.17485/ijst/2016/v9i22/95165

41. Mudarakola, L.P., Sastry, J.K.R., Vudatha, C.P., Generating test cases for testing WEB sites through neural networks and input pairs, (2014) International Journal of Applied Engineering Research, 9 (22), pp. 11819-11831. 